\title{
Management of Women with Surgically Staged 1 Uterine Papillary Serous Cancer
}

\author{
Laurie Elit, ${ }^{1}$ Andre LaRoche, ${ }^{1}$ Lauren Smith, ${ }^{1}$ John Mazurka, ${ }^{1}$ Francois Moens, ${ }^{1}$ \\ Jan Hauspy, ${ }^{1,2}$ and Waldo Jimenez ${ }^{1}$ \\ ${ }^{1}$ Department of Obstetrics and Gynecology, McMaster University, Hamilton, ON, Canada L8N3Z5 \\ ${ }^{2}$ Department of Gynecologic Oncology, St. Augustinus Hospital, L8V 5C2 Antwerp, Belgium
}

Correspondence should be addressed to Andre LaRoche, andre.laroche@usherbrooke.ca

Received 20 May 2011; Accepted 6 July 2011

Academic Editors: L. Gebrim, E. Petru, and L. B. Twiggs

Copyright (c) 2011 Laurie Elit et al. This is an open access article distributed under the Creative Commons Attribution License, which permits unrestricted use, distribution, and reproduction in any medium, provided the original work is properly cited.

Objective. To review the management and outcomes of women with surgically staged 1 UPSC. Methods. We report on a case series from 2008-2010 from Hamilton Canada. We summarize the data from a literature search on surgically staged 1 UPSC. Results. There is a group women with Stage 1A UPSC with no residual disease at time of surgery who do not require adjuvant therapy. Vault recurrences appear to be lower in women who received adjuvant vault radiation. Chemotherapy appears to confer longer survival for those women with Stage 1B or 1C disease compared of those observed or who had radiation alone. Conclusion. Adjuvant therapy appears to confer benefit in certain groups of women with stage 1 UPSC. A randomized controlled study would clarify the degree of benefit.

\section{Background}

Karpas first described an endometrial cancer with psammomatous bodies in 1963 [1]. Uterine papillary serous cancer (UPSC) was described as a distinct entity by Lauchlan in 1981 [2]. Hendricks noticed that although UPSC represented $4 \%$ of all uterine cancers; it accounted for $50 \%$ of the uterine cancer recurrences [2-10]. In fact, early stage UPSC accounted for $25 \%$ of deaths from uterine cancer [2-4, 1123 . The poor prognosis of UPSC was explained in part due to the unrecognized presence of metastatic disease at initial presentation. Goff showed that $72 \%$ of women with clinical Stage 1 UPSC had extrauterine disease at the time of surgery in comparison to a rate of $25 \%$ in women with endometrioid cancer. In Goff's study, the retroperitoneal nodes were positive in $36 \%$ of women without invasive disease, $50 \%$ with inner half myometrial involvement and 40\% with outer half myometrial involvement. Peritoneal disease was seen in $43 \%, 37 \%$, and $35 \%$, respectively [24-29]. More recently, it was noted that even surgically staged patients, who had Stage 1 UPSC, had a propensity to develop recurrent disease $[30,31]$. If women with surgically staged early disease have poor outcomes, the next questions are whether there is any adjuvant treatment that could either improve or prolong duration of survival. Our objective in this paper was to document the 2-year survival and recurrence rate of women with surgically staged 1 UPSC treated with adjuvant chemotherapy and/or radiation therapy. As no one centre has many cases, we planned to review the literature to see if any themes arose.

\section{Methods}

2.1. Case Series. In 2009, our disease site team reviewed the literature and subsequently changed out treatment policy for women with Stage 1 UPSC. We moved from observation only to offering the sandwich technique of 3 cycles of carboplatin followed by brachytherapy and then 3 further cycles of carboplatin. Women with UPSC were identified by three strategies: the pathology database at Hamilton Health Sciences Centre (this includes all surgical cases done on site and all pathology consults from the local health integrated network), the cancer centre database (this includes all new patient referrals to the cancer centre), and a review of all weekly gynaecologic oncology tumour board meeting minutes from 2008 to 
present. The search terms included serous uterine cancer and UPSC. The charts of all cases were reviewed. FIGO staging was according to the 1988 classification. Only women who were Stage 1 by surgically staging with washings, hysterectomy, bilateral salpingoophorectomy, omentectomy, and retroperitoneal node dissection were included.

Disease characteristics included depth of invasion, amount of serous component and lymphovascular space involvement. Amount of serous component was defined as pure if the specimen contained at least $90 \%$ serous cancer and mixed if it did not.

Management included chemotherapy with platinum taxane usually with carboplatin AUC 5 based on 24 collection of urinary creatinine clearance and a 3-hour infusion of paclitaxel $175 \mathrm{mg} / \mathrm{m}^{2} \mathrm{q} 3$ weeks. Radiation involved either vault brachytherapy to a dose of $1050 \mathrm{cGy}$ and/or whole pelvis radiation to $4500 \mathrm{cGy}$.

2.2. Literature Review. Search strategy included MEDLINE (1980-2011), EMBASE (1980-2011) and the Cochrane Library databases for systematic reviews and clinical trials. Reference lists of papers and review articles were scanned for additional citations. Abstracts from 1997 to 2011 annual meetings of the American Society of Clinical Oncology (ASCO) were also searched. Canadian Medical Associate (CMA) Infobase (https://mdm.ca/cpgsnew/cpgs/search/ english/help/help-glossary.html), the National Guidelines Clearinghouse (http://www.guideline.gov/), and other web sites were searched for existing evidence-based practice guide-lines. Search terms related to study design, used to search the MEDLINE and EMBASE databases, included case series, cohort studies, clinical trials meta-analysis and systematic review. The following test words and medical subject head-ings (MeSH) were used to identify the literature regard-ing adjuvant therapy in women with serous cancer of the uterine: uterine papillary serous carcinoma, drug therapy, chemotherapy, and radiation therapy. To be included in this paper, patient could have pure or mixed UPSC, all women were surgically staged Stage 1 disease, or the author indicated that the rate of surgically staging was $80 \%$ or higher and the study is about this population or we are able to pull out specific patients from the details in the patients that were surgically staged and their adjuvant management and outcomes information were clearly defined.

\section{Results}

3.1. Case Series. We report on 26 Stage 1 UPSC cases who underwent surgery. Five are excluded as they did not have retroperitoneal node dissection. There were 6 women with Stage 1A disease. All patients had residual tumour in the uterus at the final pathology. There were 10 women with Stage $1 \mathrm{~B}$ and 5 women with Stage $1 \mathrm{C}$ diseases.

In those with Stage $1 \mathrm{~A}$ disease, only 1 patient received the recommended treatment, 2 only received chemotherapy and, 3 received no treatment. In those with Stage 1B disease, 5 received carboplatin and paclitaxel plus brachytherapy, 1 received carboplatin and paclitaxel, alone and 4 received no treatment. In those with Stage $1 \mathrm{C}$ disease, 3 received carboplatin with brachytherapy, 1 received carboplatin with pelvic radiation, 1 received carboplatin alone, and 1 had no treatment. There were $2 / 9$ cases of treatment delay due to neutropenia in the group with the sandwich technique. There were $2 / 4$ cases of treatment delay due to thrombocytopenia in the chemotherapy-only group. Our disease site team had a $50 \%$ compliance with the guideline.

All patients are alive at a median of 16-month followup (range 4-40, mean 16.4 mos). There were 2 recurrences at 12 and 13 months of followup. Both were vaginal recurrences in patients with Stage 1C disease. In both cases, the patients had not received upfront radiation therapy.

3.2. Literature Search Results. There was one prospective Phase 2 study addressing feasibility and toxicity of the sandwich technique of 3 cycles of chemotherapy then radiation and 3 further cycles of chemotherapy [32]. 16 retrospective studies reported survival and recurrence outcomes for women with surgically staged Stage1 UPSC. 9 studies focused on Stage 1 disease $[22,29,33-41]$. The other 8 studies discussed all stages [28, 32, 42-47] but with enough information so that the Stage 1 patients could be identified and their outcomes were available.

3.3. Management. Most of the women in these studies began their management with surgical staging. Surgical staging involved hysterectomy, bilateral salpingoophorectomy, as well as retroperitoneal node dissection, omentectomy, and washings with or without peritoneal biopsies. The importance of surgical staging has been identified by several authors. Unlike endometrioid uterine cancer, in UPSC, metastatic disease cannot be reliably predicted based on uterine factors as women with apparent early disease (i.e., involving a polyp) may have already widespread intra-abdominal metastases. Thomas et al. [41] showed that $30 \%$ of women without clinical evidence of extrauterine disease at surgery were upstaged by the routine biopsies. Thomas et al. [41] in his series noted a clear shift in their practice in 1995 to surgically staging women with UPSC patients (i.e., at least a pelvic node dissection).

In 12 studies, women received just adjuvant chemotherapy. In 13 studies, the women received some form of adjuvant radiation: (a) vault radiation, (b) pelvic radiation, (c) whole abdominal pelvic radiation (WART), or (d) a combination of radiation techniques. In 8 studies, women received a combination of chemotherapy and one or more radiation techniques.

There is a clear bias in the retrospective studies to provide women with deeper myometrial involvement with adjuvant therapy. For example, in Elit et al. [35], 86\% of women with Stage 1A disease received no adjuvant therapy, whereas $88 \%$ with Stage 1C disease received adjuvant therapy. Conclusions about adjuvant therapy may be difficult to draw based on this bias. However, reviewing case series can help us identify some themes that would define future directions. For example, do all patients require adjuvant therapy? If there is a specific group of women such as those with no 
myometrial involvement (i.e., Stage 1A) that has excellent outcomes without adjuvant therapy, this would be important to know. If, however, all patients had poor outcomes, an argument could be made not to do extensive surgical staging and just provide adjuvant therapy.

Table 1 shows the surgical staging and histology information of the surgically staged patients included in this study. Table 2 shows the risk of recurrent disease. Certainly, there appears to be a gradient of increase risk of recurrent disease as myometrial invasion increases from Stage 1A to 1C. The numbers are low, but serous versus mixed tumours and presence or absence of lymphovascular invasion do not appear to predict recurrence.

Table 3 shows the information on different patterns of adjuvant therapy. Certainly, the only group with significant number are the women who had surgical staging and were observed. Table 4 defines the recurrence rate by adjuvant treatment and stage.

Looking at the observation group alone, there is a substantial difference in recurrence rates between those with Stage 1A and the other Stages 1B-1C.

Looking at the individual studies, some authors have advocated observation only after surgical staging and disease truly limited to the uterus [22, 28, 29, 33, 35-44, 46, 47]. Others like Kelly et al. [40] showed that the greater the myometrial invasion, the more likely a recurrence is seen with observation alone ( $43 \%$ Stage $1 \mathrm{~A}$ recurred, $77 \%$ Stage $1 \mathrm{~B}$ recurred, $80 \%$ Stage 1C recurred). There does appear to be a gradient in risk of recurrence by Stages $1 \mathrm{~A}, \mathrm{~B}, \mathrm{C}$. When focusing on Stage 1A UPSC, some authors showed no risk of relapse $[22,32]$ or a low risk of relapse up to $12 \%$ [27, 43, 4850]. Works by Hui et al. [51] and Kelly et al. [40] have shown no recurrences in women observed with Stage 1A disease without residual UPSC, this is in contrast to a $43 \%$ recurrence rate for Stage $1 \mathrm{~A}$ patients with residual uterine disease in the hysterectomy specimen who were observed. Thus, they suggest no adjuvant therapy for just those women with no residual uterine disease at time of definitive surgical staging.

Looking at whether radiation improved survival over and above observation alone, the only group that appeared to benefit was the Stage 1B population. The individual studies addressed various forms of radiation therapy. Vault radiation has been used to decrease vaginal relapse. Pelvic radiation has been used to decrease locoregional recurrence. Whole abdominal pelvic radiation therapy has been used to sterilize the whole abdominal cavity (WART).

Huh et al. [29] and Kelly et al. [40] showed that if patients with surgical Stage 1 disease were not treated with pelvic or vault radiation, there was a $10-19 \%$ chance of recurring at the vaginal vault. The risk of vault recurrence appears to be related to depth of myometrial invasion. There was a $29 \%$ rate of vault recurrence in women with Stage $1 \mathrm{~B}$ and 1C diseases in absence of adjuvant RT [41]. Vault radiation appears to decrease recurrences as compared to no adjuvant therapy. Kelly reported a vaginal recurrence rate of $19 \%(6 / 13)$ in Stage 1 UPSC in absence of adjuvant RT versus none in the 43 women who received $\mathrm{RT}(\mathrm{VB}=38$, pelvic RT $=5$ ). Use of WART in UPSC was first reported by Frank et al. [52] and others [53, 54]. The earlier studies suggested a benefit from WART in patients with Stage 1-3 disease. It was difficult to comment on outcomes of WART in Stage 1 disease given the information available. The results from adjuvant radiation alone still result in a high distant recurrence rate.

Looking at chemotherapy alone, again the numbers per strata are small, but there is a trend to markedly lower recurrences across the Stages 1A to 1C compared to observation alone or radiation. Several chemotherapy agents have been used alone or in combination for this disease. The most common agents used either alone or in combination include platinum, taxane, doxorubicin, and cyclophosphamide [8, $30,55,56]$. In the individual studies, Fader et al. $[37,38]$ showed that those 89 patients who had chemotherapy had a superior OS and PFS (81.5\% and $87.6 \%$ ) compared to those 33 women observed $(64.7 \%$ and $70.2 \%)$ and the 20 women treated with radiation $(64.1 \%$ and $59.5 \%)$. On multivariate analysis, only chemotherapy significantly and favourably impacted upon recurrence rates and PFS $(P=0.006)$. Age $(P=0.05)$, stage $(P=0.05)$, and chemotherapy $(P=0.02)$ were associated with over-all survival [38]. Kelly et al. [40] showed that in those Stage 1A patients given chemotherapy there were no recurrence compared to $43 \%$ recurrence in those not given chemo. In Stage 1B patients treated with chemotherapy, there were no recurrences compared to $77 \%$ in those not treat-ed with chemotherapy. In Stage 1C patients treated with chemotherapy, there were no recurrences compared to $80 \%$ in those not treated with chemotherapy. Overall, you had a $100 \%$ chance at survival with chemotherapy com-pared to $46 \%$ without chemotherapy. Dietrich et al. [34] showed in a multi-institutional retrospective study that all 21 surgically staged 1 patients treated with 3-6 cycles of carboplatin taxane were alive and well at a minimum of 8 mos. One had developed a vaginal recurrence that was managed with radiation. In 8 patients treated with other platinum single agent or combinations, 10-year survival was only $85 \%$ with 2 recurrences, 1 distant disease who died at 24 mos and 1 vaginal recurrence still alive after retreatment with chemotherapy and radiation. Huh et al. [29] showed no recurrences in the 7 patients treated with platinumbased chemotherapy. Fader et al. [38] showed that those with chemotherapy had a reduction in recurrences $(11.2 \%)$ com-pared to those who did not have chemotherapy $(28.3 \%$, $P=0.013)$. PFS for CT-treated patients was statistically significantly higher than for those who did not receive CT $(P=0.013)$. CT with or without RT was associated with improved PFS compared with treatment with RT also or observation $(P=0.027)$. This was most pronounced for Stage 1B patients. Overall survival did not reach statistical significance.

The problem with chemotherapy alone was a concern for the high rate of recurrences especially at the vaginal apex. Looking at that chemotherapy and radiation data, the cell sizes are larger than the chemotherapy alone data. However, the rate of recurrences by substage look similar to the chemotherapy alone data and much better than the observation alone data. The individual studies on sequential or 
TABLE 1: Characteristics of the Stage 1 UPSC studies included in this paper.

\begin{tabular}{|c|c|c|c|c|c|}
\hline Author & Publication year & Single- or multi-institutional & Time period & Number of Stage 1 patients & Median FUP mos \\
\hline Bancher-Todesca et al. [42] & 1998 & Multi & $1988-1995$ & 3 & 36 \\
\hline Bristow et al. [28] & 2001 & Single & 1989-1998 & 11 & 46 \\
\hline Carcangiu et al. [33] & 1997 & Multi & 1987-1995 & 13 & 38 \\
\hline Dietrich et al. [34] & 2005 & Multi & $1990-2003$ & 29 & 31 \\
\hline Elit et al. [35] & 2004 & Multi & 1985-2001 & 43 & 40 \\
\hline Fader et al. [36-38] & 2009 & Multi & 1993-2006 & 142 & 37 \\
\hline Fields et al. [32] & 2008 & Single & 1999-2004 & 16 & 50 \\
\hline Gallion et al. [22] & 1989 & Single & 1973-1987 & 11 & $N R$ \\
\hline Gehrig [44] & 2001 & Single & $1990-2000$ & 6 & 24 \\
\hline Grice et al. [43] & 1998 & Single & $1982-1993$ & 12 & 43 \\
\hline Huh et al. [29] & 2003 & Multi & $1987-2000$ & 60 & 30 \\
\hline Havrilesky et al. [39] & 2007 & Multi & 1976-2006 & 83 & $N R$ \\
\hline Kelly et al. [40] & 2005 & Single & 1987-2004 & 74 & $N R$ \\
\hline Low et al. [45] & 2005 & Single & 1994-2003 & 9 & 28 \\
\hline Piura et al. [46] & 1998 & Multi & 1991-1997 & 7 & 35 \\
\hline Slomovitz et al. [47] & 2003 & Single & 1989-2002 & 52 & $N R$ \\
\hline Thomas et al. [41] & 2007 & Single & $1982-2005$ & 42 & 398 \\
\hline Elit et al.* & 2011 & Single & 2008-2011 & 21 & 16 \\
\hline
\end{tabular}

* Data from Elit are not added to summary statistics as median followup is less than 24 months.

concurrent chemoradiation also suggest benefit [10, 40, 57]. Havrilesky et al. [39] showed that the 3 yr OS and PFS for chemo $(92 \%, 76 \%)$ or chemo with radiation $(89 \%, 77 \%)$ were superior to observation $(80 \%, 78 \%)$ or radiation alone $(63 \%, 44 \%)$. Fader et al. [38] showed that chemoradiation provided a superior recurrence outcome than radiation alone $(P=0.027)$. Turner showed a superior $5 \mathrm{yr}$ OS in the women receiving chemotherapy and vault RT (94\%) compared to those treated with WART + vault RT (65\%). Rosenburg et al. [8] offered 8 Stage 1 patients chemotherapy and radiation and there were no recurrences at 32 mos. Bancher-Todesca et al. [42] treated 4 Stage 1 patients with platinum and pelvic radiation and they are all alive at 39 mos. Low et al. [45] reported on 9 Stage 1 patients being treated with 4 cycles of platinum followed by pelvic radiation and in 5 cancer vault brachytherapy. There was 1 recurrence.

A novel chemoradiation approach dubbed the "sandwich technique" was evaluated by Fields et al. [32]. He conducted a prospective pilot study to assess the feasibility of 3 courses of chemotherapy, then pelvic radiation therapy followed by 3 further cycles of chemotherapy. Patients could have had any stage of UPSC. The treatment was tolerable with $97 \%$ of patients completing the intended treatment. $42 \%$ for the cycles were associated with grade $3 / 4$ neutropenia and only $3 \%$ needed a one-week treatment delay. There were no cases of febrile morbidity.

\section{Discussion}

We have pooled the data across various-case series in surgically staged women with Stage 1 UPSC. We show that the recurrence rates of those observed is significantly different in those with Stages $1 \mathrm{~B}$ and $1 \mathrm{C}$ compared to those with Stage 1A disease. We show that recurrence rates are improved especially in those with Stage $1 \mathrm{~B}$ and $1 \mathrm{C}$ diseases who receive adjuvant therapy including chemotherapy. To minimize vault recurrence, the addition of at least vault brachytherapy has been recommended. Our small case series reinforces this issue. However, the strata sizes in this study are too small to make this conclusion strongly. Although there is agreement to offer adjuvant treatment to women with Stage $1 \mathrm{~B}$ and $1 \mathrm{C}$ diseases, the evidence is not as compelling as for the adjuvant treatment of those with Stage 1A disease. There appears to be a subgroup of Stage 1A patients without residual disease in the hysterectomy specimen which has a low chance of recurrence in whom observation seems appropriate.

There are significant limitations of this paper. We use the 1988 FIGO staging system in order to compare studies using the same staging classification. Given the new 1998 FIGO staging system, the old Stages $1 \mathrm{~A}$ and $1 \mathrm{~B}$ will be collapsed into Stage 1A. The old Stage 2A will now be absorbed within Stage 1. The subtleties of management and outcomes using the old staging system will be lost when categorizing patients with new system. The plethora of small case series exist because of the relative rarity of surgically staged 1 UPSC cases. Some of the issues that exist in trying to compare these studies include that many studies involved single versus multiple centres. Data collection in multicentre studies is more likely to be stringent as a data dictionary would have been used to define and collect similar data. Most of the studies are retrospective with the exception of prospective study by Fields. Thus, there is a strong risk of bias for treatment as we saw for the women with Stages 
TABLE 2: Disease characteristics of the patients in these studies.

\begin{tabular}{|c|c|c|c|c|c|c|c|c|c|}
\hline \multirow[t]{2}{*}{ Author } & \multicolumn{3}{|c|}{ Stage (numbers) } & \multirow[b]{2}{*}{ Total } & \multirow[t]{2}{*}{ Serous } & \multirow[t]{2}{*}{ Mixed } & \multicolumn{3}{|c|}{ LVI (percent of cases) } \\
\hline & $1 \mathrm{~A}$ & $1 \mathrm{~B}$ & $1 \mathrm{C}$ & & & & + & - & Unknown \\
\hline $\begin{array}{l}\text { Bancher-Todesca et } \\
\text { al. [42] }\end{array}$ & 1 & 1 & 1 & 3 & - & - & - & - & - \\
\hline Bristow et al. [28] & 4 & 7 & - & 10 & - & - & - & - & - \\
\hline Carcangiu et al. [33] & 13 & - & - & 13 & - & - & - & - & - \\
\hline Dietrich et al. [34] & 7 & 17 & 5 & 29 & 16 & 5 & - & - & - \\
\hline Elit et al. [35] & 22 & 13 & 8 & 43 & $\begin{array}{c}36 \\
83 \%\end{array}$ & $\begin{array}{c}7 \\
17 \%\end{array}$ & - & - & - \\
\hline Fader et al. [36-38] & 51 & 65 & 26 & 142 & - & - & - & - & - \\
\hline Fields et al. [32] & 2 & 12 & 2 & 16 & - & - & - & - & - \\
\hline Gallion et al. [22] & 3 & 5 & 3 & 11 & - & - & $\begin{array}{c}7 \\
64 \%\end{array}$ & $\begin{array}{c}4 \\
36 \%\end{array}$ & - \\
\hline Gehrig [44] & 6 & - & - & 6 & - & - & $\begin{array}{c}5 \\
83 \%\end{array}$ & $\begin{array}{c}1 \\
17 \%\end{array}$ & - \\
\hline Grice et al. [43] & 4 & 4 & 4 & 12 & - & - & - & - & - \\
\hline Huh et al. [29] & 19 & 26 & 15 & 60 & $\begin{array}{c}51 \\
85 \%\end{array}$ & $\begin{array}{c}10 \\
15 \%\end{array}$ & - & - & - \\
\hline Havrilesky et al. [39] & 32 & 34 & 16 & 82 & - & - & $\begin{array}{c}18 \\
22 \%\end{array}$ & $\begin{array}{c}54 \\
65 \%\end{array}$ & $\begin{array}{c}11 \\
13 \%\end{array}$ \\
\hline Kelly et al. [40] & 33 & 29 & 12 & 74 & $\begin{array}{c}47 \\
64 \%\end{array}$ & $\begin{array}{c}27 \\
36 \%\end{array}$ & - & - & - \\
\hline Low et al. [45] & 1 & 6 & 2 & 9 & - & - & - & - & - \\
\hline Piura et al. [46] & 1 & 3 & 3 & 7 & - & - & - & - & - \\
\hline Slomovitz et al. [47] & 19 & 26 & 7 & 52 & $\begin{array}{c}27 \\
56 \%\end{array}$ & $\begin{array}{c}23 \\
44 \%\end{array}$ & $\begin{array}{c}12 \\
23 \%\end{array}$ & $\begin{array}{c}40 \\
77 \%\end{array}$ & - \\
\hline Thomas et al. [41] & 15 & 21 & 6 & 42 & - & - & - & - & - \\
\hline Elit et al.* & 6 & 10 & 5 & 21 & $\begin{array}{c}19 \\
90 \%\end{array}$ & $\begin{array}{c}2 \\
10 \%\end{array}$ & $\begin{array}{c}3 \\
14 \%\end{array}$ & $\begin{array}{c}18 \\
86 \%\end{array}$ & - \\
\hline TOTAL & 233 & 269 & 110 & 611 & $\begin{array}{c}177 / 258 \\
69 \%\end{array}$ & $\begin{array}{c}72 / 258 \\
28 \%\end{array}$ & $\begin{array}{c}42 / 151 \\
28 \%\end{array}$ & $\begin{array}{c}99 / 151 \\
66 \%\end{array}$ & $\begin{array}{c}11 / 82 \\
13 \%\end{array}$ \\
\hline
\end{tabular}

${ }^{*}$ Data from Elit are not added to summary statistics as median followup is less than 24 months.

TABLE 3: Disease recurrences by disease characteristic.

\begin{tabular}{|c|c|c|c|c|c|c|c|c|}
\hline \multirow[t]{2}{*}{ Author } & \multicolumn{3}{|c|}{ Stage } & \multirow[t]{2}{*}{ Serous } & \multirow[t]{2}{*}{ Mixed } & \multicolumn{3}{|c|}{ LVI } \\
\hline & $1 \mathrm{~A}$ & 1B & $1 \mathrm{C}$ & & & + & - & Unknown \\
\hline Bancher-Todesca et al. [42] & $0 / 1$ & $0 / 1$ & $0 / 1$ & - & - & - & - & - \\
\hline Bristow et al. [28] & $1 / 4$ & $1 / 7$ & - & - & - & - & - & - \\
\hline Carcangiu et al. [33] & $2 / 13$ & - & - & - & - & - & - & - \\
\hline Dietrich et al. [34] & $0 / 7$ & $2 / 17$ & $1 / 5$ & $3 / 16$ & $0 / 5$ & - & - & - \\
\hline Fader et al. [36-38] & $6 / 51$ & $11 / 65$ & $8 / 26$ & - & - & - & - & - \\
\hline Fields et al. [32] & 0 & $3 / 12$ & $2 / 2$ & - & - & - & - & - \\
\hline Gallion et al. [22] & $0 / 3$ & $4 / 5$ & $1 / 3$ & - & - & $5 / 7$ & 0 & - \\
\hline Gehrig [44] & $2 / 6$ & - & - & - & - & - & - & - \\
\hline Grice et al. [43] & $0 / 4$ & $0 / 4$ & $2 / 4$ & - & - & - & - & - \\
\hline Havrilesky et al. [39] & - & - & - & - & - & 18 & 53 & 11 \\
\hline Kelly et al. [40] & $6 / 33$ & $6 / 29$ & $8 / 12$ & - & - & - & - & - \\
\hline Low et al. [45] & $0 / 1$ & $1 / 6$ & $0 / 2$ & - & - & - & - & - \\
\hline Piura et al. [46] & $0 / 1$ & $0 / 3$ & $1 \mathrm{DOC} / 3$ & - & - & - & - & - \\
\hline Slomovitz et al. [47] & $4 / 19$ & - & - & - & - & - & - & - \\
\hline \multirow[t]{2}{*}{ Elit et al.* } & $0 / 6$ & $0 / 10$ & $2 / 5$ & $2 / 19$ & $0 / 2$ & $1 / 3$ & $1 / 18$ & \\
\hline & $21 / 143(15 \%)$ & $31 / 149(21 \%)$ & $22 / 56(39 \%)$ & $19 \%$ & 0 & $22 \%$ & $65 \%$ & $13 \%$ \\
\hline
\end{tabular}

${ }^{*}$ Data from Elit are not added to summary statistics as median followup is less than 24 months. 
TABLE 4: Description of management.

\begin{tabular}{|c|c|c|c|c|c|c|c|c|c|}
\hline \multirow[t]{2}{*}{ Author } & \multirow[t]{2}{*}{ Observe } & \multicolumn{5}{|l|}{ RT } & \multirow[t]{2}{*}{ CT } & \multirow{2}{*}{$\begin{array}{c}\text { CT } \\
\text { Brachy }\end{array}$} & \multirow[t]{2}{*}{ 3CT-RT-3CT } \\
\hline & & Vault & Pelvic & Pelvic + Brachy & WART & Other & & & \\
\hline Bancher-Todesca et al. [42] & 2 & - & - & 1 & - & - & - & - & - \\
\hline Bristow et al. [28] & 10 & 1 & - & - & - & - & - & - & - \\
\hline Carcangiu et al. [33] & 1 & - & - & - & 2 & - & - & 10 & - \\
\hline Dietrich et al. [34] & - & - & - & - & - & - & 28 & - & - \\
\hline Elit et al. [35] & 27 & - & 4 & - & 6 & - & 6 & - & - \\
\hline Fader et al. [36-38] & 33 & - & - & - & - & 20 & - & 89 CT with or without RT & - \\
\hline Fields et al. [32] & - & - & - & - & - & - & - & - & 16 \\
\hline Gallion et al. [22] & 5 & - & - & 6 & - & - & - & - & - \\
\hline Gehrig [44] & 6 & 一 & - & - & - & - & - & - & - \\
\hline Grice et al. [43] & 5 & - & 4 & 2 & 1 & - & - & - & - \\
\hline Huh et al. [29] & 40 & 4 & - & 5 & 3 & - & 7 & - & - \\
\hline Havrilesky et al. [39] & 47 & 7 & 10 & 4 & 9 & - & 17 & - & - \\
\hline Kelly et al. [40] & 11 & 3 & - & - & 1 & - & 21 & 8 & - \\
\hline Low et al. [45] & - & - & - & - & - & - & - & 9 & - \\
\hline Piura et al. [46] & 3 & - & - & 3 & - & - & 1 & 3 & - \\
\hline Slomovitz et al. [47] & 27 & 6 & 2 & 一 & 3 & - & 5 & 1 & - \\
\hline Thomas et al. [41] & 17 & 9 & 6 & - & 3 & - & 2 & 5 & - \\
\hline \multirow[t]{2}{*}{ Elit et al.* } & 8 & - & 一 & - & - & - & 4 & - & 9 \\
\hline & 234 & 30 & 26 & 21 & 28 & 20 & 87 & 125 & 16 \\
\hline
\end{tabular}

* Data from Elit are not added to summary statistics as median followup is less than 24 months.

TABLE 5: Recurrence rate by adjuvant treatment and stage of disease.

\begin{tabular}{|c|c|c|c|c|c|c|c|c|c|c|c|c|}
\hline \multirow[t]{2}{*}{ Author } & \multicolumn{3}{|c|}{ Observation } & \multicolumn{3}{|c|}{ Radiation } & \multicolumn{3}{|c|}{ Chemotherapy } & \multicolumn{3}{|c|}{$\mathrm{CT}+\mathrm{RT}$} \\
\hline & $1 \mathrm{~A}$ & $1 \mathrm{~B}$ & $1 \mathrm{C}$ & $1 \mathrm{~A}$ & $1 \mathrm{~B}$ & $1 \mathrm{C}$ & $1 \mathrm{~A}$ & $1 \mathrm{~B}$ & $1 \mathrm{C}$ & $1 \mathrm{~A}$ & 1B & $1 \mathrm{C}$ \\
\hline Bancher-Todesca et al. [42] & $0 / 1$ & & $0 / 1$ & & $0 / 1$ & & & & & & & \\
\hline Bristow et al. [28] & $1 / 4$ & & & & $1 / 1$ & & & & & & & \\
\hline Carcangiu et al. [33] & $0 / 1$ & & & $1 / 2$ & & & & & & $1 / 10$ & & \\
\hline Dietrich et al. [34] & & & & & & & $0 / 7$ & $2 / 17$ & $1 / 5$ & & & \\
\hline Elit et al. [35] & $2 / 19$ & $3 / 7$ & $0 / 1$ & & $0 / 5$ & $3 / 5$ & & & & & & \\
\hline Fader et al. [36-38] & $3 / 19$ & $4 / 9$ & $3 / 5$ & $1 / 5$ & $2 / 9$ & $2 / 6$ & & & & $2 / 27$ & $5 / 47$ & $3 / 15$ \\
\hline Fields et al. [32] & & & & & & & & & & $0 / 2$ & $3 / 12$ & $2 / 2$ \\
\hline Gallion et al. [22] & $0 / 3$ & $0 / 1$ & $1 / 1$ & $0 / 0$ & $4 / 4$ & $1 / 2$ & & & & & & \\
\hline Gehrig [44] & $2 / 6$ & & & & & & & & & & & \\
\hline Huh et al. [29] & & & & $1 / 3$ & $0 / 6$ & $1 / 3$ & $0 / 2$ & $0 / 3$ & $0 / 2$ & $0 / 1$ & & \\
\hline Low et al. [45] & & & & & & & & & & $0 / 1$ & $1 / 6$ & $0 / 2$ \\
\hline Piura et al. [46] & & $1 / 2$ & $\begin{array}{c}0 / 1 \\
1 \mathrm{DOC} \\
\end{array}$ & & $\begin{array}{c}0 / 3 \\
1 \mathrm{DOC}\end{array}$ & & & & $1 / 1$ & $0 / 1$ & & $0 / 2$ \\
\hline Thomas et al. [41] & $0 / 11$ & & & $0 / 3$ & & & $0 / 1$ & & & & & \\
\hline Elit et al.* & $0 / 3$ & $0 / 4$ & $1 / 1$ & & & & $0 / 2$ & $0 / 1$ & $1 / 1$ & $0 / 1$ & $0 / 5$ & $0 / 3$ \\
\hline Total & $8 / 64$ & $8 / 19$ & $4 / 9$ & $3 / 13$ & $1 / 29$ & $7 / 16$ & $0 / 10$ & $2 / 20$ & $2 / 8$ & $3 / 42$ & $9 / 65$ & $5 / 21$ \\
\hline Percent & $12.5 \%$ & $42 \%$ & $44 \%$ & $23 \%$ & $3 \%$ & $43.7 \%$ & 0 & $10 \%$ & $25 \%$ & $7 \%$ & $14 \%$ & $25 \%$ \\
\hline Stage 1A & $12.5 \%$ & & & $23 \%$ & & & 0 & & & $7 \%$ & & \\
\hline Stage 1B & & $42 \%$ & & & $3 \%$ & & & $10 \%$ & & & $14 \%$ & \\
\hline Stage 1C & & & $44 \%$ & & & $43.7 \%$ & & & $25 \%$ & & & $25 \%$ \\
\hline
\end{tabular}


TABle 6: Outcomes report by study.

\begin{tabular}{|c|c|c|c|c|c|c|}
\hline Author & $5 \mathrm{yr}$ OS & $5 \mathrm{yr}$ PFS & Other & $1 \mathrm{~A}$ & $1 \mathrm{~B}$ & $1 \mathrm{C}$ \\
\hline $\begin{array}{l}\text { Bristow et al. } \\
\text { [28] }\end{array}$ & $82 \%$ & & & & & \\
\hline $\begin{array}{l}\text { Carcangiu et al. } \\
\text { [33] }\end{array}$ & $83 \%$ & & & & & \\
\hline $\begin{array}{l}\text { Dietrich et al. } \\
\text { [34] }\end{array}$ & & $\begin{array}{l}85.7 \% \text { platinum }+ \\
\text { cyclo or platinum } \\
\text { alone } 100 \% \text { for carbo } \\
+ \text { taxol }\end{array}$ & & & & \\
\hline Fields et al. [32] & & & $\begin{array}{l}3 \text { yr OS 75\% } \\
3 \text { yr DFS 69\% }\end{array}$ & & & \\
\hline Grice et al. [43] & $84 \%$ & & $48 \mathrm{mos}^{\prime}$ & & & \\
\hline Huh et al. [29] & $72 \%$ & $70 \%$ & & & & \\
\hline $\begin{array}{l}\text { Havrilesky et al. } \\
\text { [39] }\end{array}$ & & & $\begin{array}{l}\text { Rads only } \\
3 \text { yr OS 63\% } \\
3 \text { yr PFS } 44 \% \\
\end{array}$ & $\begin{array}{c}3 \text { yr OS } 95 \%, \\
\text { PFS } 85 \%\end{array}$ & $\begin{array}{c}3 \text { yr OS } 69 \%, \\
\text { PFS } 59 \%\end{array}$ & $\begin{array}{l}3 \text { yr OS } 79 \% \text {, } \\
\text { PFS } 60 \%\end{array}$ \\
\hline Kelly et al. [40] & & & & $51 \mathrm{mos}^{\prime}$ & $37 \mathrm{mos}^{\prime}$ & $44 \mathrm{mos}^{\prime}$ \\
\hline Low et al. [45] & $73 \%$ & & & & & \\
\hline Piura et al. [46] & & & $\begin{array}{l}83.3 \% 3 \text { yr for } 10 \\
\text { patients only } 7 \\
\text { surgically staged }\end{array}$ & 34 mos' $^{\prime}$ & $46 \mathrm{mos}^{\prime}$ & $35 \mathrm{mos}^{\prime}$ \\
\hline $\begin{array}{l}\text { Slomovitz et al. } \\
{[47]}\end{array}$ & $63 \%$ & & & 5 yr OS $81.5 \%$ & 5 yr OS $58.6 \%$ & $5 \mathrm{yr}$ OS $34.3 \%$ \\
\hline $\begin{array}{l}\text { Thomas et al. } \\
{[41]}\end{array}$ & $85 \%$ & $78 \%$ & & 5 yr OS $100 \%$ & 5 yr OS $89 \%$ & 5 yr OS $60 \%$ \\
\hline
\end{tabular}

5 yr OS.

DFS: disease free survival.

': Median survival.

$1 \mathrm{~B}$ and 1C. In earlier reports, management results grouped UPSC with other high-grade cancers like clear cell; thus, it was difficult to discern the outcome of the UPSC cases and likely those cases were excluded. Many earlier studies reported on all stages of UPSC or a combination of Stages 1 and 2 versus focusing in on just Stage 1. Again, the information from these studies was likely excluded. The quality of the surgical staging varied across studies, that is, retroperitoneal node dissection only versus addition of omentectomy and peritoneal biopsies. Many earlier studies report their "experience with UPSC" and describe several adjuvant treatment strategies with small number of cases in each strata. Bias in choosing a management strategy is clearly an issue here. The radiation techniques varied across studies. Follow-up time in some studies was short, that is, 3 years; however, most recurrences were noted within the first 2 years after treatment, thus the impact of this short follow-up is not as concerning as may be the case in other disease types.

A randomized study provides the best opportunity for defining management. However, given the limitations listed about a randomized study in this rare entity is unlikely. This study of the current literature does provide themes around improvements for care in women with Stage 1 UPSC. There appears to be a role for chemotherapy in preventing the high rate of distant disease. There appears to be a role for some form of radiation, either vault brachytherapy or whole pelvic radiation to decrease the high risk of vault relapses.

\section{References}

[1] C. M. Karpas and M. F. Bridge, "Endometrial adenocarcinoma with psammomatous bodies," American Journal of Obstetrics and Gynecology, vol. 87, pp. 935-941, 1963.

[2] S. C. Lauchlan, "Tubal (serous) carcinoma of the endometrium," Archives of Pathology and Laboratory Medicine, vol. 105, no. 11, pp. 615-618, 1981.

[3] M. Hendrickson, J. Ross, P. Eifel, A. Martinez, and A. Martinez, "Uterine papillary serous carcinoma. A highly malignant form of endometrial adenocarcinoma," American Journal of Surgical Pathology, vol. 6, no. 2, pp. 93-108, 1982.

[4] M. Hendrickson, J. Ross, P. J. Eifel, R. S. Cox, A. Martinez, and R. Kempson, "Adenocarcinoma of the endometrium: analysis of 256 cases with carcinoma limited to the uterine corpus. Pathology review and analysis of prognostic variables," Gynecologic Oncology, vol. 13, no. 3, pp. 373-392, 1982.

[5] H. J. Spjut, R. H. Kaufman, and S. S. Carrig, "Psammoma bodies in the cervico-vaginal smear," Acta Cytologica, vol. 8, pp. 352-355, 1964.

[6] K. Hameed and D. A. Morgan, "Papillary adenocarcinoma of endometrium with psammoma bodies. Histology and fine structure," Cancer, vol. 29, no. 5, pp. 1326-1335, 1972.

[7] V. A. LiVolsi, "Adenocarcinoma of the endometrium with psammoma bodies," Obstetrics and Gynecology, vol. 50, no. 6, pp. 725-728, 1977.

[8] P. Rosenberg, R. Blom, T. Hogberg, and E. Simonsen, "Death rate and recurrence pattern among 841 clinical stage I endometrial cancer patients with special reference to uterine 
papillary serous carcinoma," Gynecologic Oncology, vol. 51, no. 3, pp. 311-315, 1993.

[9] P. Rosenberg, B. Risberg, L. Askmalm, and E. Simonsen, “The prognosis in early endometrial carcinoma. The importance of uterine papillary serous carcinoma (UPSC), age, FIGO grade and nuclear grade," Acta Obstetricia et Gynecologica Scandinavica, vol. 68, no. 2, pp. 157-163, 1989.

[10] B. C. Turner, J. P.S. Knisely, B. M. Kacinski et al., "Effective treatment of Stage I uterine papillary serous carcinoma with high dose-rate vaginal apex radiation (192Ir) and chemotherapy," International Journal of Radiation Oncology Biology Physics, vol. 40, no. 1, pp. 77-84, 1998.

[11] M. E. Sherman, P. Bitterman, N. B. Rosenshein, G. Delgado, and R. J. Kurman, "Uterine serous carcinoma: a morphologically diverse neoplasm with unifying clinicopathologic features," American Journal of Surgical Pathology, vol. 16, no. 6, pp. 600-610, 1992.

[12] V. M. Abeler and K. E. Kjorstad, "Serous papillary carcinoma of the endometrium: a histopathological study of 22 cases," Gynecologic Oncology, vol. 39, no. 3, pp. 266-271, 1990.

[13] B. G. Ward, R. G. Wright, and K. Free, "Papillary carcinomas of the endometrium," Gynecologic Oncology, vol. 39, no. 3, pp. 347-351, 1990.

[14] J. F. Jeffrey, G. V. Krepart, and R. J. Lotocki, "Papillary serous adenocarcinoma of the endometrium," Obstetrics and Gynecology, vol. 67, no. 5, pp. 670-674, 1986.

[15] R. P. Matthews, J. Hutchinson-Colas, M. Maiman et al., "Papillary serous and clear cell type lead to poor prognosis of endometrial carcinoma in black women," Gynecologic Onco$\log y$, vol. 65, no. 2, pp. 206-212, 1997.

[16] G. P. Sutton, L. Brill, H. Michael, F. B. Stehman, and C. E. Ehrlich, "Malignant papillary lesions of the endometrium," Gynecologic Oncology, vol. 27, no. 3, pp. 294-304, 1987.

[17] J. T. Chambers, M. Merino, and E. I. Kohorn, "Uterine papillary serous carcinoma," Obstetrics and Gynecology, vol. 69, no. 1, pp. 109-113, 1987.

[18] M. L. Carcangiu and J. T. Chambers, "Uterine papillary serous carcinoma: a study on 108 cases with emphasis on the prognostic significance of associated endometrioid carcinoma, absence of invasion, and concomitant ovarian carcinoma," Gynecologic Oncology, vol. 47, no. 3, pp. 298-305, 1992.

[19] K. R. Lee and J. L. Belinson, "Papillary serous adenocarcinoma of the endometrium: a clinicopathologic study of 19 cases," Gynecologic Oncology, vol. 46, no. 1, pp. 51-54, 1992.

[20] C. J. Dunton, G. Balsara, M. McFarland, and E. Hernandez, "Uterine papillary serous carcinoma: a review," Obstetrical and Gynecological Survey, vol. 46, no. 2, pp. 97-102, 1991.

[21] W. M. Christopherson, R. C. Alberhasky, and P. J. Connelly, "Carcinoma of the endometrium. II. Papillary adenocarcinoma: a clinical pathological study 46 cases," American Journal of Clinical Pathology, vol. 77, no. 5, pp. 534-540, 1982.

[22] H. H. Gallion, J. R. Van Nagell, D. F. Powell et al., "Stage I serous papillary carcinoma of the endometrium," Cancer, vol. 63, no. 11, pp. 2224-2228, 1989.

[23] C. E. Ramirez-Gonzalez, K. Adamsons, T. Y. MangualVazquez, and R. C. Wallach, "Papillary adenocarcinoma in the endometrium," Obstetrics and Gynecology, vol. 70, no. 2, pp. 212-215, 1987.

[24] A. Goodman and B. Goff, "Endometrial cancer: screening, diagnosis and Surgical Staging," Clinical Obstetrics and Gynecology, vol. 13, pp. 739-750, 1986.

[25] B. A. Goff, D. Kato, R. A. Schmidt et al., "Uterine papillary serous carcinoma: patterns of metastatic spread," Gynecologic Oncology, vol. 54, no. 3, pp. 264-268, 1994.
[26] P. A. Gehrig, P. A. Groben, W. C. Fowler, L. A. Walton, and L. Van Le, "Noninvasive papillary serous carcinoma of the endometrium," Obstetrics and Gynecology, vol. 97, no. 1, pp. 153-157, 2001.

[27] J. K. Chan, V. Loizzi, M. Youssef et al., "Significance of comprehensive surgical staging in noninvasive papillary serous carcinoma of the endometrium," Gynecologic Oncology, vol. 90, no. 1, pp. 181-185, 2003.

[28] R. E. Bristow, F. Asrari, E. L. Trimble, and F. J. Montz, "Extended surgical staging for uterine papillary serous carcinoma: survival outcome of locoregional (stage 1-3) disease," Gynecologic Oncology, vol. 81, no. 2, pp. 279-286, 2001.

[29] W. K. Huh, M. Powell, C. A. Leath III et al., "Uterine papillary serous carcinoma: comparisons of outcomes in surgical Stage I patients with and without adjuvant therapy," Gynecologic Oncology, vol. 91, no. 3, pp. 470-475, 2003.

[30] K. M. Zanotti, J. L. Belinson, A. W. Kennedy, K. D. Webster, and M. Markman, "The use of paclitaxel and platinumbased chemotherapy in uterine papillary serous carcinoma," Gynecologic Oncology, vol. 74, no. 2, pp. 272-277, 1999.

[31] A. N. Walker and S. E. Mills, "Serous papillary carcinoma of the endometrium. A clinicopathologic study of 11 cases," Diagnostic Gynecology and Obstetrics, vol. 4, no. 4, pp. 261267, 1982.

[32] A. L. Fields, M. H. Einstein, A. P. Novetsky, J. Gebb, and G. L. Goldberg, "Pilot phase II trial of radiation "sandwiched" between combination paclitaxel/platinum chemotherapy in patients with uterine papillary serous carcinoma (UPSC)," Gynecologic Oncology, vol. 108, no. 1, pp. 201-206, 2008.

[33] M. L. Carcangiu, L. K. Tan, and J. T. Chambers, "Stage 1A uterine serous carcinoma: a study of 13 cases," American Journal of Surgical Pathology, vol. 21, no. 12, pp. 1507-1514, 1997.

[34] C. S. Dietrich, S. C. Modesitt, P. D. Depriest et al., "The efficacy of adjuvant platinum-based chemotherapy in Stage I uterine papillary serous carcinoma (UPSC)," Gynecologic Oncology, vol. 99, no. 3, pp. 557-563, 2005.

[35] L. Elit, J. Kwon, J. Bentley, K. Trim, I. Ackerman, and M. Carey, "Optimal management for surgically Stage 1 serous cancer of the uterus," Gynecologic Oncology, vol. 92, no. 1, pp. 240-246, 2004.

[36] A. N. Fader, D. Boruta, A. B. Olawaiye, and P. A. Gehrig, "Uterine papillary serous carcinoma: epidemiology, pathogenesis and management," Current Opinion in Obstetrics \& Gynecology, vol. 22, no. 1, pp. 21-29, 2010.

[37] A. N. Fader, R. D. Drake, D. M. O’Malley et al., "Platinum/Taxane-based chemotherapy with or without radiation therapy favourably impacts survival outcomes in stage 1 uterine papillary serous carcinoma," Cancer, vol. 115, pp. 2119-2127, 2009.

[38] A. N. Fader, D. Starks, P. A. Gehrig et al., "An updated clinicopathologic study of early-stage uterine papillary serous carcinoma (UPSC)," Gynecologic Oncology, vol. 115, no. 2, pp. 244-248, 2009.

[39] L. J. Havrilesky, A. Alvarez Secord, V. Bae-Jump et al., "Outcomes in surgical stage 1 uterine papillary serous carcinoma," Gynecologic Oncology, vol. 105, pp. 677-682, 2007.

[40] M. G. Kelly, D. M. O'Malley, P. Hui et al., "Improved survival in surgical stage I patients with uterine papillary serous carcinoma (UPSC) treated with adjuvant platinumbased chemotherapy," Gynecologic Oncology, vol. 98, no. 3, pp. 353-359, 2005. 
[41] M. B. Thomas, A. Mariani, W. A. Cliby, G. A. Keeney, K. C. Podratz, and S. C. Dowdy, "Role of systematic lymphadenectomy and adjuvant therapy in stage I uterine papillary serous carcinoma," Gynecologic Oncology, vol. 107, no. 2, pp. 186189, 2007.

[42] D. Bancher-Todesca, W. Neunteufel, K. E. Williams et al., "Influence of postoperative treatment on survival in patients with uterine papillary serous carcinoma," Gynecologic Oncology, vol. 71, no. 3, pp. 344-347, 1998.

[43] J. Grice, M. Ek, B. Greer et al., "Uterine papillary serous carcinoma: evaluation of long-term survival in surgically staged patients," Gynecologic Oncology, vol. 69, no. 1, pp. 6973, 1998.

[44] P. A. Gehrig, "Uterine papillary serous carcinoma: a review," Expert Opinion on Pharmacotherapy, vol. 8, no. 6, pp. 809-816, 2007.

[45] J. S. H. Low, E. H. Wong, H. S. K. Tan et al., "Adjuvant sequential chemotherapy and radiotherapy in uterine papillary serous carcinoma," Gynecologic Oncology, vol. 97, no. 1, pp. 171-177, 2005.

[46] B. Piura, M. Meirovitz, M. Shmulman, I. Yanai-Inbar, Y. Cohen, and R. Dgani, "Uterine papillary serous carcinoma: study of 19 cases," European Journal of Obstetrics Gynecology and Reproductive Biology, vol. 79, no. 1, pp. 69-73, 1998.

[47] B. M. Slomovitz, T. W. Burke, P. J. Eifel et al., "Uterine papillary serous carcinoma (UPSC): a single institution review of 129 cases," Gynecologic Oncology, vol. 91, no. 3, pp. 463-469, 2003.

[48] P. S. Craighead, K. Sait, G. C. Stuart et al., "Management of aggressive histologic variants of endometrial carcinoma at the Tom Baker Cancer Centre between 1984 and 1994," Gynecologic Oncology, vol. 77, no. 2, pp. 248-253, 2000.

[49] M. G. Kelly, D. O'Malley, P. Hui et al., "Patients with uterine papillary serous cancers may benefit from adjuvant platinumbased chemoradiation," Gynecologic Oncology, vol. 95, no. 3, pp. 469-473, 2004.

[50] N. E. Tchabo, S. McCloskey, T. L. Mashtare et al., "Treatment of early-stage uterine papillary serous carcinoma at Roswell Park Cancer Institute, 1992-2006," Gynecologic Oncology, vol. 115, no. 2, pp. 249-256, 2009.

[51] P. Hui, M. Kelly, D. M. O’Malley, F. Tavassoli, and P. E. Schwartz, "Minimal uterine serous carcinoma: a clinicopathological study of 40 cases," Modern Pathology, vol. 18, no. 1, pp. 75-82, 2005.

[52] A. H. Frank, P. C. Tseng, B. G. Haffty et al., "Adjuvant wholeabdominal radiation therapy in uterine papillary serous carcinoma," Cancer, vol. 68, no. 7, pp. 1516-1519, 1991.

[53] P. Lim, A. Al Kushi, B. Gilks, F. Wong, and C. Aquino-Parsons, "Early stage uterine papillary serous carcinoma of the endometrium: effect of adjuvant whole abdominal radio-therapy and pathologic parameters on outcome," Cancer, vol. 91, no. 4, pp. 752-757, 2001.

[54] G. Sutton, J. H. Axelrod, B. N. Bundy et al., "Adjuvant whole abdominal irradiation in clinical stages I and II papillary serous or clear cell carcinoma of the endometrium: a phase II study of the Gynecologic Oncology Group," Gynecologic Oncology, vol. 100, no. 2, pp. 349-354, 2006.

[55] F. V. Price, "Intravenous cisplatin, doxorubicin, and cyclophosphamide in the treatment of uterine papillary serous carcinoma (UPSC)," Gynecologic Oncology, vol. 51, no. 3, pp. 383 $389,1993$.

[56] J. T. Chambers, S. K. Chambers, E. I. Kohorn, M. L. Carcangiu, and P. E. Schwartz, "Uterine papillary serous carcinoma treated with intraperitoneal cisplatin and intravenous doxorubicin and cyclophosphamide," Gynecologic Oncology, vol. 60, no. 3, pp. 438-442, 1996.
[57] B. M. Sood, J. Jones, S. Gupta et al., "Patterns of failure after the multimodality treatment of uterine papillary serous carcinoma," International Journal of Radiation Oncology Biology Physics, vol. 57, no. 1, pp. 208-216, 2003. 


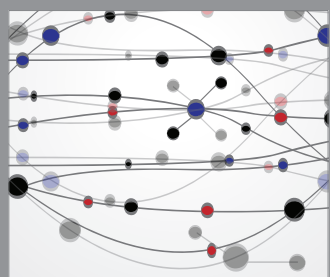

The Scientific World Journal
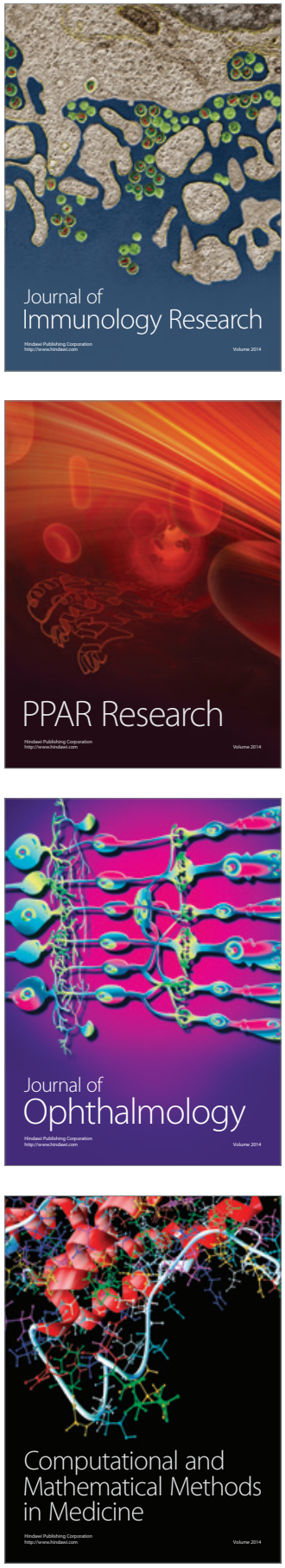

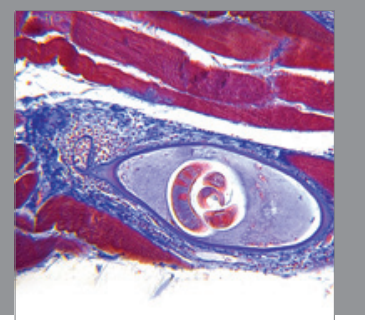

Gastroenterology

Research and Practice
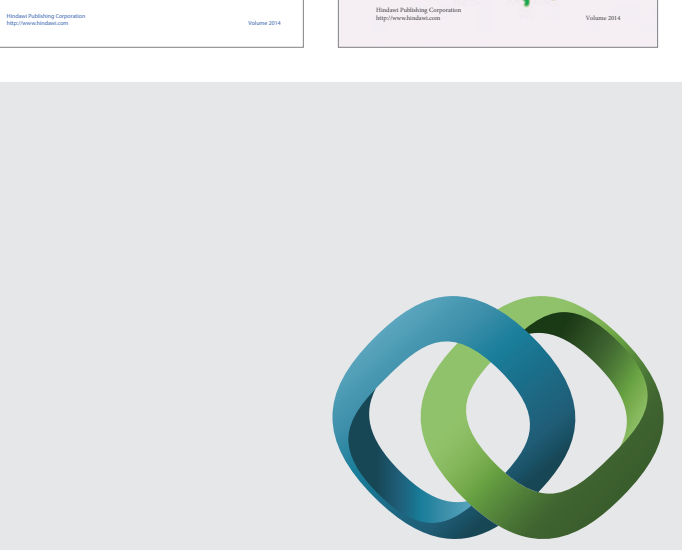

\section{Hindawi}

Submit your manuscripts at

http://www.hindawi.com
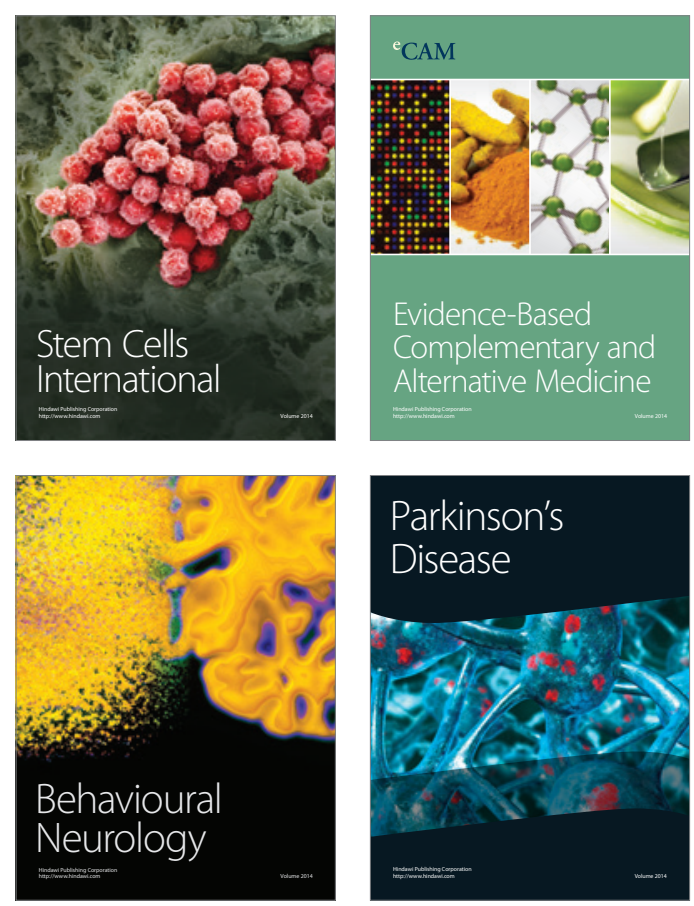

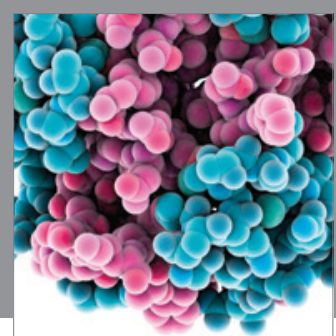

Journal of
Diabetes Research

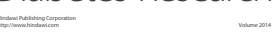

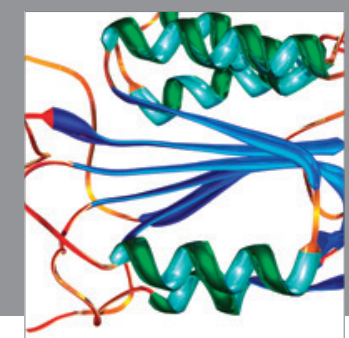

Disease Markers
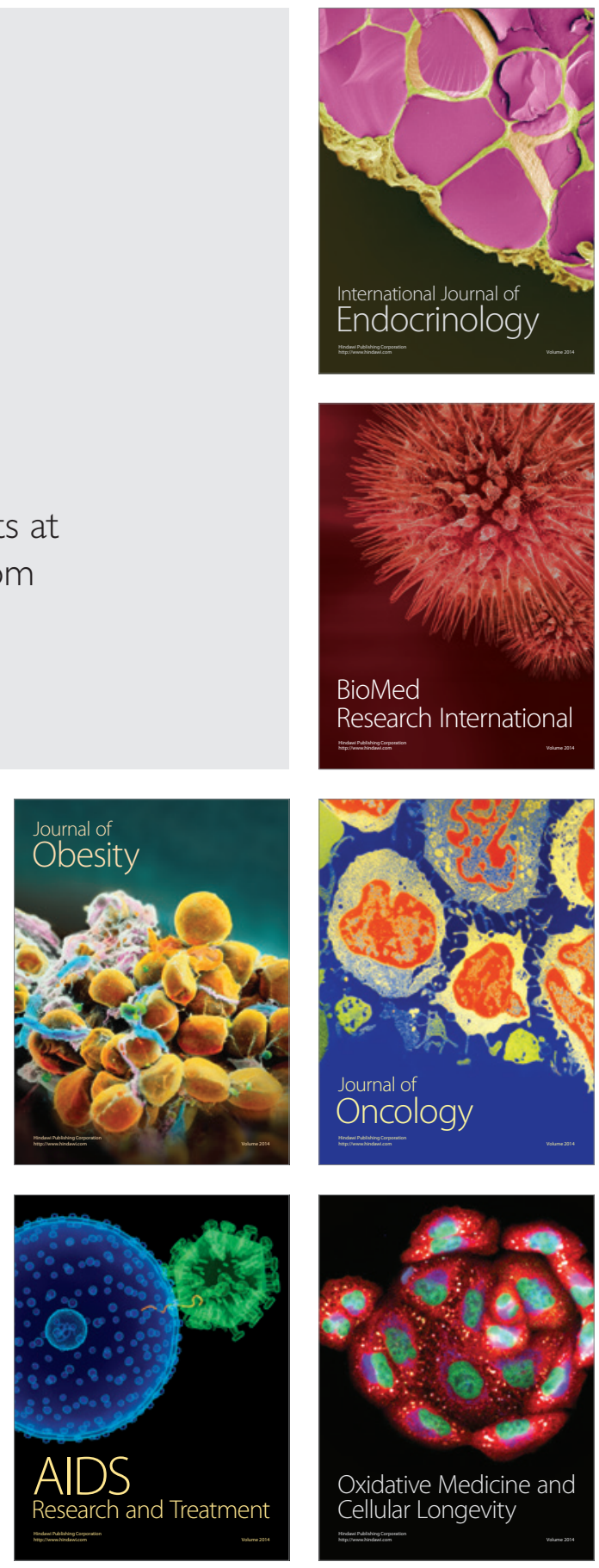